\title{
Perceptions of the declining quality of higher education in the selected SEE countries
}

\author{
Veselin Draskovic \\ University of Social Sciences, Poland; \\ University of Montenegro, Montenegro \\ veso-mimo@,t-com.me \\ ORCID 0000-0003-3968-422X
}

\section{Radislav Jovovic}

Mediteranean University,

Podgorica, Montenegro

radejovovi@@,t-com.me

\section{Jarosław Rychlik}

Research and Development Institute, Higher School of Criminology and Penitentiary Science in Warsaw, Warsaw, Poland

ORCID 0000-0002-1948-1882

Abstract. The subject of this paper is to point out phenomenologically the causes of the evident decline in the quality of higher education in the selected countries of the Southeast Europe: Bosnia and Herzegovina (B\&H), Montenegro (MNE) and Serbia (SER). The aim of this research is comparing respondents' perceptions in the above countries regarding the basic and general causes of decline in higher education levels, which is generated by massive negative (braking) processes and tendencies. It starts with the hypothesis that most problems in higher education of the considered countries originate for two reasons: application of the political principle of the voting machine and selective application of the so-called "Bologna Process" in the field of higher education. The multiple regression linear approach is methodologically applied to the sample of 210 respondents in the three countries mentioned above. The results have confirmed the validity of the hypothesis and, consequently, the need for significant educational reforms in the part of the independent variables, which would lead to an increase in the quality of higher education.

Keywords: higher education, Bosnia and Herzegovina, Montenegro, Serbia, multiple regression linear approach.

JEL Classification: I23 


\section{INTRODUCTION}

Knowledge (intellectual competitiveness) is a motto of the new information era. Higher education is of particular importance for the economic competitiveness of any society (Bloom et al., 2006, p. 16; Qerimi \& Sergi, 2017; Żyra, 2019). It is an infrastructure for future state-level social cohesiveness. Besides, it contributes to state competitiveness (Akimova et al., 2020; Bilan et al., 2020; Green et al., 2010; Luchko, Arzamasova \& Vovk, 2019; Volchik et al., 2018). It is generally considered that higher education is the leading area for the provision of competitive capabilities and competitive advantages of businesses (and the state) since it directly affects the creation of intellectual and organizational capital. (Sułkowski et. al., 2020). Higher education in the observed transitional countries is facing a great crisis. A huge number of people have a university degree, and at the same time many of them do not know proper spelling, not to mention methodological illiteracy or more complex forms of knowledge. The massiveness of higher education is not harmonized with the employment policies, nor with the adequate development strategy. Under the conditions of low level of knowledge and science, with small investments in it, the hasty borrowing and application of the world's highest criteria in education is perilous. The contemporary education system is made up of people, who are the sole culprits for the inefficient functioning of the related institutions, that is, for the inconsistent and irresponsible implementation of all forms of elections (political, economic, educational and other). The method of political "merged courts" into the higher education system of the considered states reflected the political principle of domination of rigged and privileged elections (abuse) at all levels of decision-making (Draskovic, 2018, pp. 5, 54, 78; Bush and Prather, 2018). That has resulted in the accumulation of functions in the hands of the same persons, the negative selection of personnel, the formalization and decline of scientific criteria, and consequently to a drastic decrease in the quality level of higher education and scientific knowledge. Thus, through the (probably programmed, devised) process of diploma inflation (not backed up by real knowledge) and the award of undeserved scientific titles and senior positions in the system of higher education, there was a worrying and paradoxical equalization of scientific knowledge and ignorance.

\section{THEORETICAL FRAMEWORK}

In the midst of the general application of quasi-neoliberal ideology (from the field of economic policy to institutions - Draskovic et al., 2019), higher education, by inertia, divided the general destiny of society. (Ibid.) It is considered that in the observed countries of South-eastern Europe in the field of higher education there was a conscious replacement of theses: instead of the civilizational imperative, much greater investment in science and higher education, a chaotic "Bologna declaration" was introduced, which from the beginning of its application to today proved multifaceted. We have repeatedly suggested that in order to achieve sustainable development, it is necessary to significantly increase investment in science and education (i.e. knowledge in general) (Tarabasz et al., 2018; Dzimińska et al., 2020; Sułkowski et al., 2019). Many other authors have insisted on this (Sedziuviene \& Vveinhardt, 2018, p. 226; Mikalauskiene \& Atkociuniene, 2019; Tamasevicius et al., 2020; Tóth et al., 2020), particularly, investigating effects of intellectual capital restoring considering the impact of external migration (Bilan et al., 2019; Mishchuk et al., 2019;). Let's remember e.g. that during his visit to the considered countries in 2017, Nobel laureate E. Maskin graciously and precisely said: "If you want better (economic) results, invest in education". The statistics, unfortunately, shows that investment in science in the countries under consideration is very small, near $0.2 \%$ of GDP in Bosnia and Herzegovina, and approximately $0.3-0.4 \%$ of GDP in Montenegro and Serbia.

The fact is that there are a number of factors affecting the quality of higher education in our hypothetical model, which cannot be fully defined. It is especially difficult to determine the true degree of influence of individual factors (independent variables in our model) on the quality of higher education 
(dependent variable in our model). Therefore, we decided to test hypothetically four basic groups of independent variables, which in our opinion determinate the quality of higher education, namely:

- Iv1 - The negative impact of general and long-term crisis, with unbalanced social values, and reduced criteria. It implies the affirmation and reproduction of false value systems (effect of path dependence - Arthur, 1994; Tortorella at al., 2020) and cultural factors: mentality, education and social consent - Delibasic, 2016), which in the field of higher education reflects through achievements (diplomas, titles, vocations) without proper investments (learning, scientific work, references, and knowledge). Directly related to this are: palliative, improvisational, ignorant, and irresponsible attempts to reform science, applied by ignorant and interests-driven reformers. They shift on key functions by model in the elective (excessively long) mandates, by the procedure where voting outcome is known in advance, and later by the subjective choice of the closest associates.

- Iv2 - The impact of unlearned competitive advantages of individuals, referred to by T. West, S. Ravenscroft, and C. Shrader (2004), relates to the following phenomena: increased number of instances in which the scientific title has no coverage in knowledge, to the deficit of original research, mercantilization of higher education, selection of non-referential staff in higher scientific titles, manipulation of multidisciplinarity (Kravchenko, 2019), destruction of the principles of scientific verticality, abolition of departments, false presentation of scientific references and citations, use of cabinet (fictitious) data, misstatement of master's and master's degrees etc.

- Iv3 - The impact of decline in scientific competence of colleges and universities, which is associated with the longterm forcing of infantilization and imitation of science, the hyper-production of scientific staff, study programs, faculties and diplomas (at all levels), shutting down scientific institutes as temples of scientific research and poor financing of science, the underestimation and relativization of real scientific results (national scientific monographs, national scientific journals, and everything that requires long-term, devoted, and competent scientific and team work) - Draskovic, 2018, p. 96.

- Iv4 - The impact of immoral university externalities is related to plagiarism, corruption, failure to teach, erosion of ethical standards, transformation of craft disciplines into scientific ones, underestimation of real scientific authorities, etc.

Due to the above-mentioned reasons, a dangerous process of higher education quality reduce is being developed. As a consequence, its inadequacy to the real needs of society becomes obvious, especially in the part of employment (Vlasov et al., 2020). Besides, some researchers prove that higher education does not always lead to greater feeling of own security at the labour market (Lewandowska \& Stopa, 2020). Of course, many are wondering whether the considered negative factors (which most often act as processes) are programmed, with the aim of defusing, through mass diploma inflation, the diplomas of all those hardearned (before transition) graduates, to dull their critical blade and to undergo the rigid and imposed totalitarization of consciousness.

\section{CASE STUDY}

For this research, we have conceived questionnaires in accordance to the previously presented theoretical framework. In total 210 highly qualified persons with high level of logical thinking from Bosnia and Herzegovina (70), Montenegro (70), and Serbia (70) have been interviewed. They were asked to evaluate, based on their best knowledge, experience and (or) intuition, the dependent variable in the model, defined as the "quality of bigher education" (each respondent for the corresponding in his/her own country). Also, they were asked to evaluate the values of the negative influence of the four independent variables in the model (listed above) on the dependent variable. The scheme of our research framework is given in Figure 1. 


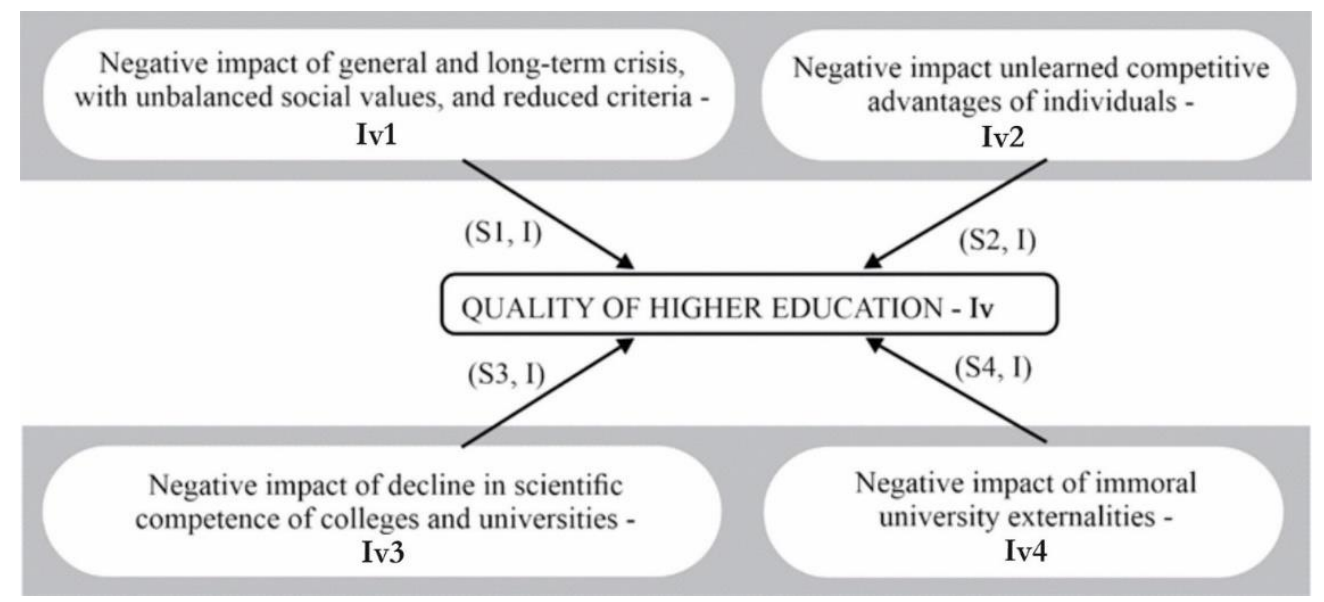

Figure 1. Research framework

Source: own

The constructs from the research framework were measured with point $1 ; 1,5 ; 2 ; 2,5 ; 3 ; 3,5 ; 4 ; 4,5 ; 5$ Likert-type multi-item scale. In fact, the respondents used linguistic qualifications: very strong (5), strong (4), medium (3), weak (2) and very weak (1) to answer the questions. These qualifications were later coded into Likert's scale as it is noted in the brackets next to each of the linguistics qualification. In the next section is described shortly multiple linear regression model which we used for the responds quantitative analysis. Designing the survey and the analysis took into consideration the existing similar political, economic, cultural and institutional conditions in the countries concerned. Following regression analysis have included both separate and integral data for all three considered groups.

\section{LINEAR MULTIPLE REGRESSION MODEL}

The idea is to determine functional relationship between the dependent variable (Dv): quality of bigher education and independent ones (Iv1, Iv2, Iv3 and Iv4).

Our goal was to estimate the realistically expected mean value of the dependent variable $(\overline{D v})$, based on individual estimation of the respondents. Since the respondents have estimated the dependent variable Dv and independent variables (Iv1, Iv2, Iv3 and Iv4) on their own discretion, our task was, in line with the requirements of multiple linear regression, to determine the coefficients: $I, S_{1}, S_{2}, S_{3}$ and $S_{4}$, and to calculate $\overline{D v}$, using Eq. (1):

$$
\overline{D v}=I+S 1 * D v 1+S 2 * D v 2+S 3 * D v 3+S 4 * D v 4
$$

Where,

$\overline{D v}$ - is the mean expected value of the dependent variable;

$\mathrm{I}$ - is the intercept, determined on the basis of an appropriate sample;

$S_{1}, S_{2}, S_{3}$ and $S_{4}-$ are coefficients of independent variables $I_{1}, I_{2}, I_{3}$, and $I_{4}$, or slopes of the correspondent lines. This practically means that for any new value of each independent variable from a predefined interval, we can estimate the value of the dependent variable. It should be said that $\overline{D v}$ is an average estimated value, since it is a mean value of $\mathrm{Iv}_{1}, \mathrm{Iv}_{2}, \mathrm{Iv}_{3}$ and $\mathrm{Iv}_{4}$. To determine $\overline{D v}$ it is used the last square method (Bertskas et al., 2008). In fact, our goal was to determine the coefficients: $I, S_{1}, S_{2}, S_{3}$ and $S_{4}$, so as to minimize the sum of squared errors (SSE), which is represented by Eq. (2): 


$$
\begin{aligned}
& S S E=\sum_{k=1}^{n}\left(D v_{k}-\overline{D v}_{k}\right)^{2}= \\
& =\sum_{k=1}^{n}\left(D v_{k}-(I+S 1 * I v 1+S 2 * I v 2+S 3 * I v 3+S 4 * I v 4)\right)^{2}
\end{aligned}
$$

Where,

$D v_{k}$ - is actual value of the dependent variable, given by the $\mathrm{k}$ respondents $(k=\overline{1, n})$;

$\overline{D v}_{k}$ - is the estimated value of the dependent variable on the basis of the model, in the case of $\mathrm{k}$ respondents $(k=\overline{1, n})$;

$\mathrm{n}-$ is the total number of respondents $(300$ of them from Bosnia and Herzegovina, Montenegro, and Serbia), $k=\overline{1, n}$.

Using the least-squares method, here is actually determined a straight line, which minimizes the sum of vertical differences for each pair of points (Balakrishnan et al., 2007). In other words, identified is a straight line that best fits the given set of points, by determining the optimal value of intercept (I), as well as coefficients $\left(\mathrm{S}_{1}, \mathrm{~S}_{2}, \mathrm{~S}_{3}\right.$, and $\left.\mathrm{S}_{4}\right)$, in order to obtain a more accurate value of $\overline{\boldsymbol{D} v}$ for the given (estimated) values of $\mathrm{Iv}_{1}, \mathrm{Iv}_{2}, \mathrm{Iv}_{3}$, and $\mathrm{Iv}_{4}$, and $\mathrm{Dv}$ (for $\forall k, k=\overline{1, n}$ ).

\section{RESULTS AND DISCUSSION}

The obtained results are shown in Table 1. In addition to the coefficients: S0, S1, S2, and S4, the following statistical indicators were determined: mean absolute deviation (MAD), correlation coefficient $r$, coefficient of determination ( $\mathrm{r} 2$ ), mean square error (MSE), mean absolute percent error (MAPE), and standard error of regression estimate (SE). These indicators show high model correspondence and respondents' estimates;

Table 1

Key parameters and statistics in a multiple linear regression model

\begin{tabular}{|c|c|c|c|}
\hline Param. & $\begin{array}{c}\text { Case 1: } \\
\text { Bosnia\&Herzegovina }\end{array}$ & $\begin{array}{c}\text { Case 2: } \\
\text { Montenegro }\end{array}$ & Case 3: Serbia \\
\hline B0 & $-1,261$ & $-1,350$ & $-0,036$ \\
\hline B1 & 0,839 & 0,733 & 0,539 \\
\hline B2 & 0,069 & 0,055 & $-0,006$ \\
\hline B3 & 0,110 & 0,177 & 0,046 \\
\hline B4 & 0,003 & 0,094 & 0,091 \\
\hline r & 0,865 & 0,886 & 0,596 \\
\hline r2 & 0,748 & 0,750 & 0,467 \\
\hline MAD & 0,230 & 0,255 & 0,463 \\
\hline MSE & 0,133 & 0,126 & 0,347 \\
\hline MAPE & $11,28 \%$ & $11,58 \%$ & $20,75 \%$ \\
\hline SE & 0,370 & 0,360 & 0,61 \\
\hline
\end{tabular}

Source: own

In accordance with the data shown in Table 1, the lines representing the functional dependency between the dependent (Dv) and the independent variables $\left(I v_{1-4}\right)$ are below. 
Case 1. Bosnia and Herzegovina (B\&H)

$$
\begin{gathered}
\bar{Y}=I+S 1 I v_{1}+S 2 I v_{2}+S 3 I v_{3}+S 4 I v_{4} \\
\overline{Y_{\text {B\&H }}}=-1,261+0,839 \times I v_{1}+0,069 \times I v_{2}+0,110 \times I v_{3}+0,003 \times I v_{4}
\end{gathered}
$$

Case 2: Montenegro (MNE):

$$
\begin{gathered}
\bar{Y}=I+S 1 I v_{1}+S 2 I v_{2}+S 3 I v_{3}+S 4 I v_{4} \\
\mathrm{Y}_{\mathrm{MNE}}=-1,261+0,839 \times I v_{1}+0,069 \times I v_{2}+0,110 \times I v_{3}+0,003 \times I v_{4}
\end{gathered}
$$

Case 3: Serbia (SER)

$$
\begin{gathered}
\bar{Y}=I+S 1 I v_{1}+S 2 I v_{2}+S 3 I v_{3}+S 4 I v_{4} \\
\overline{\mathrm{Y}_{\mathrm{SER}}}=-0,036+0,539 \times I v_{1}-0,006 \times I v_{2}+0,046 \times I v_{3}+0,091 \times I v_{4} .
\end{gathered}
$$

The average values of the dependent variable estimated by the respondents are shown in Graph 1, expressed in \% for all analysed countries: Bosnia and Herzegovina. Montenegro, Serbia, it is clear that the percentage of respondents (over 35\%) from all three countries rated the quality of higher education as low (2.0). A significant percentage of respondents opted for a grade 3.0.

According to the linear dependence analyses between the dependent variable and the mean values of independent variables (Graph 2), it is clear that variables $\mathrm{Iv}_{3}$ have the most pronounced influence on the dependent variable. Ranking the lowest is the variable $\mathrm{I}_{1}$, variable $\mathrm{I}_{2}$ is second, and variable $\mathrm{I}_{4}$ is third. These analyses were performed over the entire sample. Based on individual sample analyses (from Bosnia and Herzegovina, Montenegro, Serbia), a level of influence of independent variables on the dependent variable was obtained (Table 2).

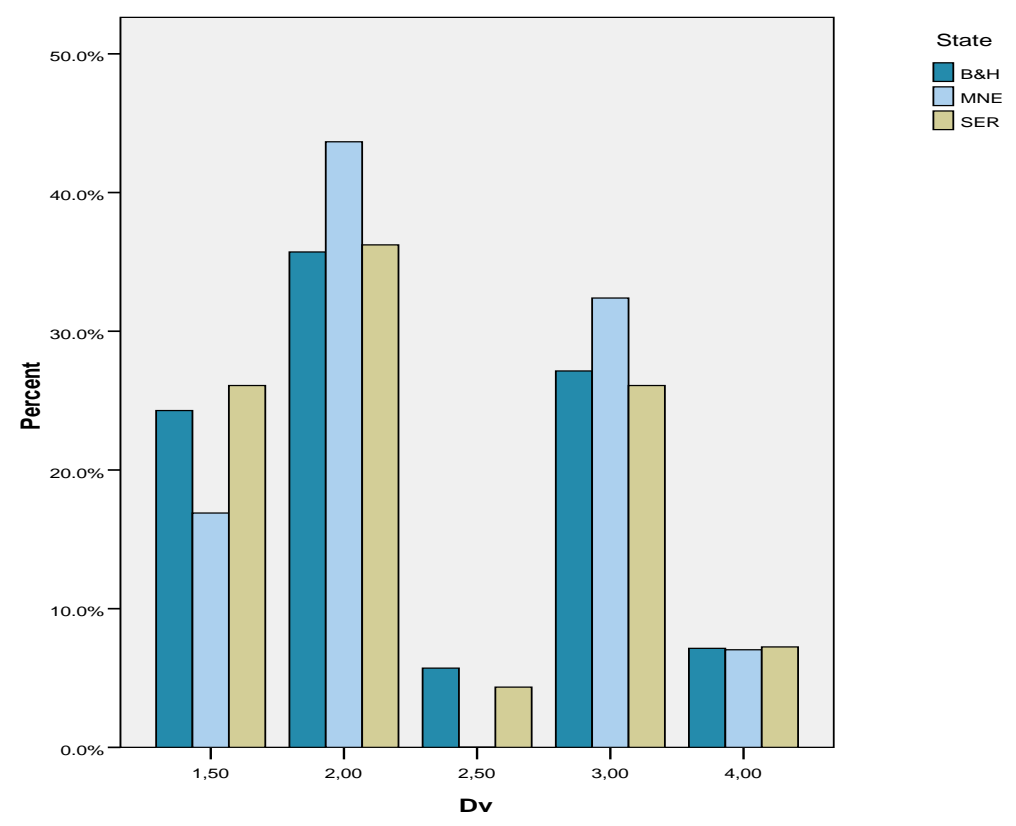

Graph 1. Percentage of estimates 1 to 5 in the set of dependent variables (Dv)

Source: own 


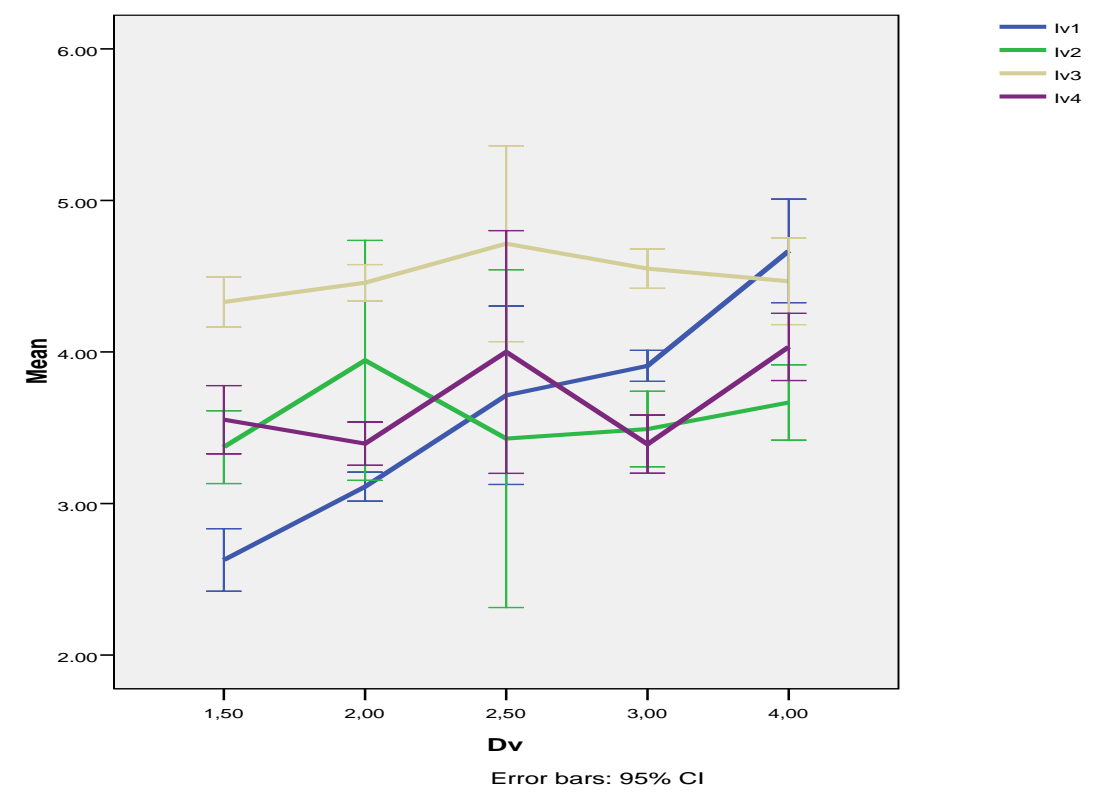

Graph 2: The dependent variable (Dv) vs independent variables $\left(\mathbf{I v}_{1-4}\right)$ in the model

Source: own

In accordance with the mean values of independent variables (Table 2), it can be concluded that decline in scientific competence of colleges and universities (Iv3), has the greatest influence on the quality of higher education in Montenegro, Bosnia and Herzegovina, and Serbia. Unlearned competitive advantages of individuals (Iv2) has the second most significant influence in Bosnia and Herzegovina, and Serbia, while immoral university externalities (Iv4) in Montenegro. On the other hand, general and long-term crisis (Iv1) has the weakest impact in all cases.

Table 2

Mean values of independent variables $\left(I_{1-4}\right)$ and rank of their influence on the dependent variable $(\mathrm{Y})$

\begin{tabular}{|c|c|c|c|}
\hline Level & $\begin{array}{c}\text { Case 3: } \\
\text { Bosnia\& Herzegovina }\end{array}$ & Case 1: Montenegro & Case 2: Serbia \\
\hline 1 & $\mathrm{I} 3[4,535]$ & $\mathrm{I} 3[4,321]$ & $\mathrm{I} 3[4,535]$ \\
\hline 2 & $\mathrm{I} 4[3,528]$ & $\mathrm{I} 2[3,514]$ & $\mathrm{I} 2[3,964]$ \\
\hline 3 & $\mathrm{I} 2[3,471]$ & $\mathrm{I} 4[3,464]$ & $\mathrm{I} 4[3,492]$ \\
\hline 4 & $\mathrm{I} 1[3,371]$ & $\mathrm{I} 1[3,314]$ & $\mathrm{I} 1[3,400]$ \\
\hline
\end{tabular}

Source: own

The correlation coefficient and the coefficient of determination show that the model largely explains the variance of the dependent variable (Table 3)

Table 3

Model quality indicators

\begin{tabular}{|l|l|l|}
\hline$R$ & $R^{2}$ & Standard error \\
\hline $0,791 \mathrm{a})$ & 0,731 & 0,391 \\
\hline
\end{tabular}

Source: own 


\section{CONCLUSION}

There are many problems in selected SEE countries that threaten social and economic development: institutional, economic, cultural, value, socio-pathological, educational and others. All of them have a composite and negative effect on the selective and inconsistent application of the so-called the "Bologna Convention", which was wrongly and tendentiously proclaimed the "Bologna Declaration", thus (wrongly) reinforcing its obligation. Due to the degeneration of the "Bologna process", the quality of higher education decreased.

The deliberate application of the political principle of the voting machinery in the field of higher education has enabled the realization of many negative phenomena in practice, which have led to the collapse of scientific, moral and educational criteria, and consequently to the decline in the quality of higher education in the observed countries. The esteems of 210 respondents, participated in our survey, allow to define the arithmetic average in B\&H (2.51), in MNE (2.64), and in SER (2.58). All independent variables have had a significant impact on the decline of higher education quality. Long-term crisis with unbalanced social values have had a slightly weaker impact. Decline in scientific competence of colleges and universities has the greatest influence. Two other independent variables made approximately the same and very strong impact.

\section{ACKNOWLEDGEMENT}

The author, Jarosław Rychlik, is grateful for the possibilities of training, provided by co-authors of this article. Gained professional experience and data, collected within training program, allow to contribute to the research.

\section{REFERENCES}

Akimova, L. M., Khomiuk, N. L., Bezena, I. M., Lytvynchuk, I. L., \& Petroye, O. (2020). Planning of socio-economic development of the territories (experience of European Union). International Journal of Management, 11(4).

Arthur, W.B. (1994). Increasing Returns and Path Dependence in the Economy. Ann Arbor, MI: University of Michigan.

Balakrishnan, N., Render, B., \& Stair, R.M. (2007). Managerial decision modeling with spreadsheets. New Jersey: PrenticeHall Inc.

Bertskas, D.P., \& Tsitsiklis, J.N. (2008). Introduction to probability. USA: Athena Scientific.

Bilan, Y., Mishchuk, H., Roshchyk, I., \& Kmecova I. (2020). Analysis of intellectual potential and its impact on the social and economic development of European Countries. Journal of Competitiveness, 1, 22-38. https://doi.org/10.7441/joc.2020.01.02

Bilan, S., Mishchuk, H., Bilan, Y., \& Mishchuk, V. (2019). Empirical study of migration caused by well-being in living and working environment. Paper presented at the Proceedings of the 34th International Business Information Management Association Conference, IBIMA 2020: Vision 2025: Education Excellence and Management of Innovations through Sustainable Economic Competitive Advantage, 11159-11169.

Bloom, D., Canning, D., Chan, K. (2006). Higher education and economic development in Africa. Harvard: Harvard University. Bush, S.S., \& Prather, L. (2018). Who's There? Election observer identity and the local credibility of elections. International Organization. 72(3), 659-692.

Delibasic, M. (2016). Hypothetical matrix for institutional modeling of the basis for economic development in the countries of Southeast Europe. Montenegrin Journal of Economics. 12(2), 147-159.

Draskovic, V. (2018). Clokotrism of transition: critical essays on social paradoxes, Celje: Scientific Publishing Hub.

Draskovic, V., Draskovic, M., \& Bilan, S. (2019). Motivation, Methodology, and Phenomenology of Institutional Nihilism in the SEE Countries. Montenegrin Journal of Economics. 15(2), 7-14.

Dzimińska, M., Fijałkowska, J., \& Sułkowski, Ł. (2020). A conceptual model proposal: universities as culture change agents for sustainable development. Sustainability, 12(11), 4635. 
Green, A., Mostafa, T., \& Preston, J. (2010). The Chimera of Competitiveness: Varieties of Capitalism and the Economic Crisis. Centre for Learning and Life Chances in Knowledge Economies and Societies. http://www.llakes.org.uk (downloads 12.11.2019)

Kravchenko, S.A. (2019). Increasingly complex techno-digital realities in the dynamics of scientific discourse. Montenegrin Journal of Economics. 15(4), 225-237.

Lewandowska, A., \& Stopa, M. (2020). The impact of innovative professional qualifications on the sense of employment security: Evidence from Poland. Economics and Sociology, 13(3), 72-83. doi:10.14254/2071789X.2020/13-3/5

Luchko, M., Arzamasova, O., \& Vovk, I. (2019). Personnel potential of national economy and gross domestic product: The case of Ukraine. Montenegrin Journal of Economics, 15(2), 59-70.

Mikalauskiene, A., \& Atkociuniene, Z. (2019). Knowledge Management Impact on Sustainable Development. Montenegrin Journal of Economics. 15(4), 149-160.

Mishchuk, H., Roshchyk, I. Sułkowska, J., \&Vojtovič, S. (2019). Prospects of assessing the impact of external student migration on restoring the country's intellectual potential (case study of Ukraine). Economics and Sociology, 12(3), 209-219. doi:10.14254/2071-789X.2019/12-3/14

Qerimi, Q., \& Sergi, B. S. (2017). The nature and the scope of the global economic crisis' impact on employment trends and policies in South East Europe. Journal of International Studies, 10(4), 143-153. doi:10.14254/2071$8330.2017 / 10-4 / 11$

Sedziuviene, N., \& Vveinhardt, J. (2018). The Reactions of Post-Soviet Countries Employees to Changes Carried Out by Organizations in Higher Education: Cases of Lithuanian, Ukrainian and Belarusian State Colleges. Montenegrin Journal of Economics. 14(4), 225-235.

Sułkowski, Ł., Fijałkowska, J., \& Dzimińska, M. (2019). Mergers in higher education institutions: a proposal of a novel conceptual model. Managerial Finance, 45(10/11), 1469-1487

Sułkowski, L., Przytuła, S., Borg, C., \& Kulikowski, K. (2020). Performance Appraisal in Universities-Assessing the Tension in Public Service Motivation (PSM). Education Sciences, 10(7), 174.

Tamasevicius, V., Diskiene, D., \& Stankeviciene, A. (2020). Human Resource Management Practice in Lithuania: Evidences and Challenges. Montenegrin Journal of Economics, 16(1), 207-226.

Tarabasz, A., Selaković, M., \& Abraham, Ch. (2018). The Classroom of the Future: Disrupting the Concept of Contemporary Business Education. Entrepreneurial Business and Economics Review, 6(4), 231-245. https://doi.org/10.15678/EBER.2018.060413

Tortorella, G.L., Cawley Vergara, A.M., Garza-Reyes, J.A., \& Sawhney, R. (2020). Organizational learning paths based upon industry 4.0 adoption: An empirical study with Brazilian manufacturers. International Journal of Production Economics, 219, 284-294.

Tóth, A., Juhász, T., \& Kálmán, B. (2020). The role of innovation and human factor in the development of East Central Europe. Montenegrin Journal of Economics, 16(1), 251-274.

Vlasov, M., Panikarova, S., Draskovic, M., \& Draskovic, V. (2020). Evaluating University Academic Efficacy: Institutional Approach. Montenegrin Journal of Economics, 16(1), 241-250.

Volchik, V., Oganesyan, A., \& Olejarz, T. (2018). Higher education as a factor of socio-economic performance and development. Journal of International Studies, 11(4), 326-340. doi:10.14254/2071-8330.2018/11-4/23

West, T., Ravenscroft, S., \& Shrader, C. (2004). Cheating and Moral Judgment in the College Classroom: A Natural Experiment. Journal of Business Ethics, 54, 173-183.

Żyra, J. (2019). Student Enrolment and Output Effects in Poland: 2SLS and VAR Estimates. Entrepreneurial Business and Economics Review, 7(4), 131-146. https://doi.org/10.15678/EBER.2019.070408 